\title{
Marine stratocumulus aerosol-cloud relationships in the MASE-II experiment: Precipitation susceptibility in eastern Pacific marine stratocumulus
}

\author{
Miao-Ling Lu, ${ }^{1}$ Armin Sorooshian, ${ }^{2,3,4}$ Haflidi H. Jonsson, ${ }^{5}$ Graham Feingold, ${ }^{2}$ \\ Richard C. Flagan, ${ }^{1,6}$ and John H. Seinfeld ${ }^{1,6}$ \\ Received 1 July 2009; revised 21 September 2009; accepted 28 September 2009; published 22 December 2009.
}

[1] Observational data on aerosol-cloud-drizzle relationships in marine stratocumulus are presented from the second Marine Stratus/Stratocumulus Experiment (MASE-II) carried out in July 2007 over the eastern Pacific near Monterey, California. Observations, carried out in regions of essentially uniform meteorology with localized aerosol enhancements due to ship exhaust ("ship tracks"), demonstrate, in accord with those from numerous other field campaigns, that increased cloud drop number concentration $N_{c}$ and decreased cloud top effective radius $r_{e}$ are associated with increased subcloud aerosol concentration. Modulation of drizzle by variations in aerosol levels is clearly evident. Variations of cloud base drizzle rate $R_{\mathrm{cb}}$ are found to be consistent with the proportionality, $R_{\mathrm{cb}} \propto H^{3} / N_{c}$, where $H$ is cloud depth. Simultaneous aircraft and A-Train satellite observations are used to quantify the precipitation susceptibility of clouds to aerosol perturbations in the eastern Pacific region.

Citation: Lu, M.-L., A. Sorooshian, H. H. Jonsson, G. Feingold, R. C. Flagan, and J. H. Seinfeld (2009), Marine stratocumulus aerosol-cloud relationships in the MASE-II experiment: Precipitation susceptibility in eastern Pacific marine stratocumulus,

J. Geophys. Res., 114, D24203, doi:10.1029/2009JD012774.

\section{Introduction}

[2] Improving understanding of the response of clouds to aerosol perturbations is a high priority in climate change predictions [Intergovernmental Panel on Climate Change, 2007]. Changes in aerosol levels impact cloud microphysics; as well, effects on cloud-scale dynamics must be accounted for to understand fully the cloud response to aerosol forcing. Parameterizations of the responses of clouds to aerosol forcing remain crude, in part, because these involve processes at scales that are not accessible to global climate models (GCMs) but also because complete understanding of the feedbacks on cloud behavior is lacking.

[3] An overall objective of an observational approach to aerosol-cloud relationships in climate is to quantify the relative susceptibilities of cloud properties to changes in the general circulation and to internal microphysical changes induced by aerosol perturbations [Brenguier and

\footnotetext{
${ }^{\mathrm{I}}$ Department of Environmental Science and Engineering, California Institute of Technology, Pasadena, California, USA.

${ }^{2}$ Chemical Sciences Division, Earth System Research Laboratory, NOAA, Boulder, Colorado, USA.

${ }^{3}$ Cooperative Institute for Research in the Atmosphere, Colorado State University, Fort Collins, Colorado, USA.

${ }^{4}$ Now at Department of Chemical and Environmental Engineering, University of Arizona, Tucson, Arizona, USA.

${ }^{5}$ Naval Postgraduate School, Monterey, California, USA.

${ }^{6}$ Department of Chemical Engineering, California Institute of Technology, Pasadena, California, USA.
}

Copyright 2009 by the American Geophysical Union. 0148-0227/09/2009JD012774\$09.00
Wood, 2009]. To optimize the chances of distinguishing an aerosol signal from background meteorological variability, the experimental region should be one in which cloud perturbations due to aerosol variability significantly exceed those due to meteorological variability and in which the covariation of meteorological variability with the aerosol variability is at a minimum. Owing to their climatic importance, marine stratocumulus ( $\mathrm{Sc}$ ) have served as a focus for studies of aerosol-cloud relationships. The classic case exhibiting the susceptibility of marine Sc to aerosol perturbations is that of ship tracks, e.g., Noone et al. [2000] and Platnick and Twomey [1994], where over a relatively welldefined spatial scale the aerosol variability substantially exceeds natural meteorological variability.

[4] We report here on the second of two field experiments aimed at exploring aerosol-cloud relationships in the climatically important regime of eastern Pacific marine stratocumulus. Two phases of the Marine Stratus/Stratocumulus Experiment (MASE) were conducted over the eastern Pacific Ocean off the coast of Monterey, California; the first phase (MASE-I) was undertaken in July 2005 [ $L u$ et al., 2007], and the second phase (MASE-II) was carried out in July 2007. Each experiment employed the Center for Interdisciplinary Remotely Piloted Aircraft Studies Twin Otter aircraft. During MASE-I, 13 cloud cases were sampled, 6 of which exhibited significant aerosol perturbations; 1 ship track case was analyzed in detail. During MASE-II, 5 flights (Table 1) out of 16 encountered strong, localized perturbations in aerosol concentration, evidently ship tracks, in contrast to the neighboring unperturbed clouds. An 
Table 1. Summary of Selected Research Flights and Observed Cloud Properties During MASE-II ${ }^{\mathrm{a}}$

\begin{tabular}{|c|c|c|c|c|c|c|c|c|c|c|}
\hline $\begin{array}{c}\text { Research } \\
\text { Flight }^{\mathrm{b}}\end{array}$ & Flight Date & $\begin{array}{c}\text { Cloud Sampling } \\
\text { Time (UTC) }\end{array}$ & $\begin{array}{c}\text { Cloud } \\
\text { Base }(\mathrm{m})\end{array}$ & $\begin{array}{c}\text { Cloud } \\
\text { Depth }(\mathrm{m})\end{array}$ & $N_{a}\left(\mathrm{~cm}^{-3}\right)$ & $w\left(\mathrm{~m} \mathrm{~s}^{-1}\right)$ & $N_{c}\left(\mathrm{~cm}^{-3}\right)$ & $N_{c, \text { ad }}\left(\mathrm{cm}^{-3}\right)$ & $\begin{array}{c}\text { LWP } \\
\left(\mathrm{g} \mathrm{m}^{-2}\right) \\
\end{array}$ & $\begin{array}{c}\begin{array}{c}R_{\mathrm{cb}} \\
\left(\mathrm{mm} \mathrm{d}^{-1}\right)\end{array} \\
\end{array}$ \\
\hline RF8_1 & 22 July 2007 & $1622-1833$ & 120 & 330 & $243 \pm 239$ & 0.26 & $67 \pm 32$ & $106 \pm 24$ & 46 & 2.69 \\
\hline RF8_2 & 22 July 2007 & $1844-2000$ & 130 & 210 & $234 \pm 73$ & 0.68 & $84 \pm 28$ & $117 \pm 17$ & 21 & 0.68 \\
\hline RF10 & 24 July 2007 & $1633-1941$ & 180 & 510 & $731 \pm 135$ & 0.44 & $155 \pm 57$ & $225 \pm 78$ & 126 & 0.70 \\
\hline RF11_1 & 25 July 2007 & $1645-1925$ & 440 & 460 & $786 \pm 32$ & 0.91 & $153 \pm 43$ & $196 \pm 15$ & 82 & 1.05 \\
\hline RF11_2 & 25 July 2007 & $1926-2017$ & 440 & 220 & $696 \pm 190$ & 2.21 & $192 \pm 40$ & $188 \pm 14$ & 29 & 0.14 \\
\hline RF14_1 & 29 July 2007 & $1553-1734$ & 180 & 420 & $348 \pm 263$ & 0.30 & $105 \pm 47$ & $123 \pm 27$ & 97 & 0.93 \\
\hline RF14_2 & 29 July 2007 & $1735-1914$ & 200 & 280 & $359 \pm 152$ & 0.11 & $114 \pm 34$ & $124 \pm 20$ & 45 & 1.12 \\
\hline RF16_1 & 31 July 2007 & $1541-1730$ & 170 & 515 & $1271 \pm 106$ & 0.32 & $300 \pm 44$ & $312 \pm 32$ & 143 & 0.59 \\
\hline RF16_2 & 31 July 2007 & $1742-1935$ & 270 & 400 & $1433 \pm 1700$ & 0.28 & $164 \pm 80$ & $360 \pm 71$ & 63 & 0.62 \\
\hline
\end{tabular}

${ }^{a}$ Cloud top and base are obtained as shown in Figure 5. Aerosol number concentration $\left(N_{a}\right)$ is the total aerosol number concentration, measured by the condensation particle counter (CPC) with smallest cutoff size of $10 \mathrm{~nm}$ (in diameter). $N_{a}$ and updraft velocity $(w)$ are the leg-mean values measured at or near cloud base; $w$ is calculated only for positive values. Cloud droplet number concentration $\left(N_{c}\right)$ is the leg-mean value averaged over the height range $1 / 6<z^{*}<5 / 6$, where $z^{*}$ is the normalized height with respect to cloud depth. Adiabatic cloud droplet number concentration $\left(N_{c \text {,ad }}\right)$ is calculated over the adiabatic region with the adiabatic ratio greater than 0.8 and minimal drizzle. LWP is the vertical integration of the leg-mean LWC. Cloud base drizzle rate $\left(R_{\mathrm{cb}}\right)$ is the precipitation rate calculated at the near cloud base leg. Cloud properties, e.g., $N_{c}$, LWC, and LWP, are obtained from the Forward Scattering Spectrometer Probe (FSSP) data; drizzle data, e.g., $R_{\mathrm{cb}}$, are obtained from the cloud imaging probe (CIP) as part of the cloud/aerosol/precipitation spectrometer (CAPS) package. Cloud and drizzle properties are averaged in the cloudy regions only. The quantity after the plus/minus is the standard deviation. Local time equals UTC minus $7 \mathrm{~h}$. Sampling frequency of the data is $1 \mathrm{~Hz}$. A horizontal leg is about $40 \mathrm{~km}$ with $50 \mathrm{~m}$ spatial resolution.

${ }^{b} \mathrm{RF}$ denotes research flight. The number after the underline denotes the first or second sampling.

aircraft flight strategy was employed to locate ship emissions in the below-cloud aerosol and subsequently to probe the vertical distribution of cloud droplet properties and above-cloud aerosol in adjacent unperturbed and ship track regions. Instrumentation on board the Twin Otter in MASE-II is given by Hersey et al. [2009]. Flight data analysis is described in Table 1 and as in the MASE-I experiment [Lu et al., 2007]. Simultaneous measurements from NASA's A-Train constellation of satellites [Stephens et al., 2002] are also compared to aircraft measurements to quantify the precipitation susceptibility of clouds to aerosol perturbations in the region. The goal of the present work is to evaluate aerosol-cloud-drizzle relationships from the MASE-II experiment.

\section{Ship Tracks Case Study}

[5] Figure 1 shows the flight path on 22 July 2007 (research flight (RF) 8), during which two ship tracks were encountered. The flight strategy typically consisted of a below-cloud horizontal leg, a near-base leg, two or three incloud legs, and one cloud top leg. In Figure 1, two ship tracks can be discerned from the aerosol number concentration, denoted by the black dotted lines (left-hand side (LHS) and right-hand side (RHS)). The two ship tracks are evident from the aerosol number concentrations and higher cloud droplet number concentration $\left(N_{c}\right)$ measured in the horizontal flight legs in the lower and middle portions of the cloud (Figure 2). Figure 3a shows the relationship between cloud droplet mean radius and $N_{c}$ from the middle leg of the cloud. The data have been sorted according to the extent to which the vertical liquid water content (LWC) profile is adiabatic, as represented by the adiabatic ratio [Pawlowska et al., 2006; Lu et al., 2008], $A R_{L}=\mathrm{LWC} / \mathrm{LWC}_{\mathrm{ad}}$, where $\mathrm{LWC}_{\mathrm{ad}}$ is the adiabatic liquid water content: quasi-adiabatic, $A R_{L} \geq 0.8$ (blue); moderately diluted, $0.8>A R_{L} \geq 0.5$ (green); and strongly diluted, $A R_{L}<0.5$ (red). An inverse relationship between cloud droplet mean radius $\left(r_{m}\right)$ and $N_{c}$ is evident after sorting for those data points, reflecting a closer approach to an adiabatic profile (blue and green colors). At the same degree of dilution, the ship track regions, in general, exhibit smaller droplets than the unperturbed regions.

[6] The cloud droplet size spectrum can also be affected by the aerosol concentration, the so-called dispersion effect, the magnitude and direction of which depend on condensational processes, droplet collision coalescence, and cloud dynamics (e.g., updraft and entrainment) [Liu and Daum, 2002; Lu and Seinfeld, 2006]. The dispersion effect is typically quantified by means of the relative dispersion $(d)$, defined as the ratio of the standard deviation ( $\sigma$, or cloud droplet spectral width) to the mean radius of the cloud droplet size distribution. Analysis of the effect requires accurate measurement of the full cloud droplet spectrum. A factor limiting the analysis of droplet spectral dispersion is the inadequacy of the Forward Scattering Spectrometer Probe instrument to resolve the cloud droplet size distribution at the small size end. Figure $3 \mathrm{~b}$ shows the relationship between relative dispersion and cloud droplet number concentration from the leg shown in Figure 2b. In the absence of sorting, the entire data set exhibits an inverse $N_{c}-d$ relationship. The higher values of $d$ ranging from 0.3 to 0.8 are associated with strongly nonadiabatic data points (red) and an inverse relationship between $d$ and $N_{c}$; no obvious $N_{c}-d$ relationship is evident for those data points that more closely approach adiabatic conditions (green and blue), and these points are associated with smaller values of $d$ of about $0.15-0.4$. The data suggest that the fine-scale $N_{c^{-}} d$ relationship depends upon both aerosol number concentration and the departure from adiabaticity. In Figure 3b, data points are also classified into ship track (crosses and asterisks) and clean (open triangles and squares) regions. The ship track regions are characterized generally by smaller cloud droplet dispersion than the counterpart clean regions (i.e., more open triangles and squares are clustered at the larger dispersion values).

[7] The cloud droplet number distributions from three different regimes in the $N_{c}-d$ relationship (denoted A, B, and $\mathrm{C}$ in Figure $3 \mathrm{~b}$ ) are shown in Figure 3c. Curve $\mathrm{A}$ represents low $N_{c}$ and high dispersion. Curve $\mathrm{C}$ is the data with high $N_{c}$, and curve B represents a middle case. Each 

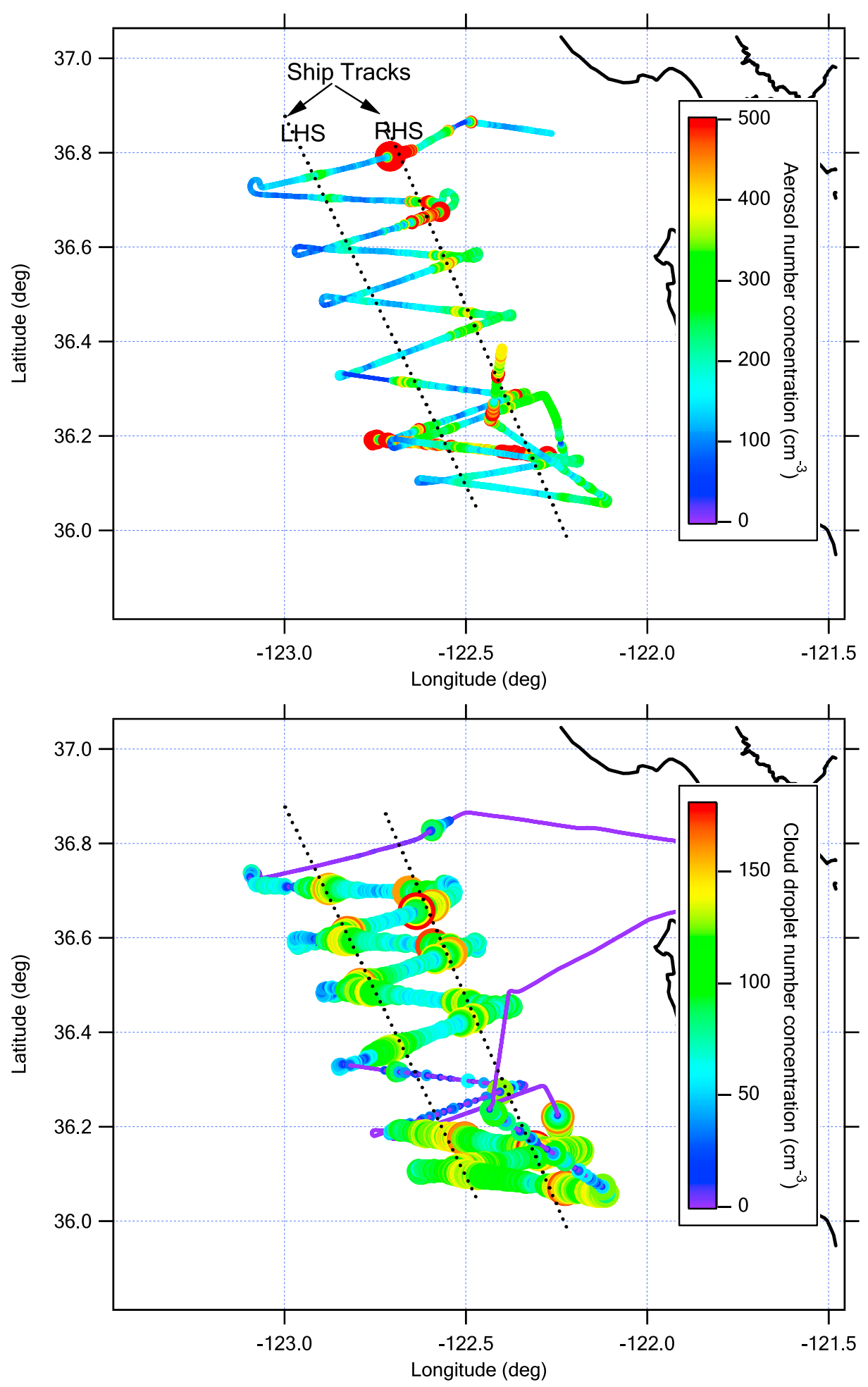

Figure 1. (top) Aerosol and (bottom) cloud droplet number concentration sampled on 22 July 2007 (RF8) during the MASE-II campaign. Ship tracks are evident from the aerosol number concentration, denoted by the black dotted lines (left-hand side (LHS) and right-hand side (RHS)). Symbols are sized according to the aerosol or cloud droplet number concentration.

curve has about a factor of 2 difference in $N_{c}$. Comparing distributions $\mathrm{B}$ and $\mathrm{C}, \mathrm{C}$ is predominantly a shift of distribution $\mathrm{B}$ to smaller sizes, which can be simply explained by the Twomey effect. The most interesting feature is the difference between distributions $\mathrm{A}$ and $\mathrm{B}$.
The cloud droplet size distribution is broadened at the tails at both large and small sizes. Curve $\mathrm{A}$ also shows significantly reduced $N_{c}$ and the largest drizzle drop number concentration among the three classes. Therefore, the broadening is most likely attributed to the effect of 

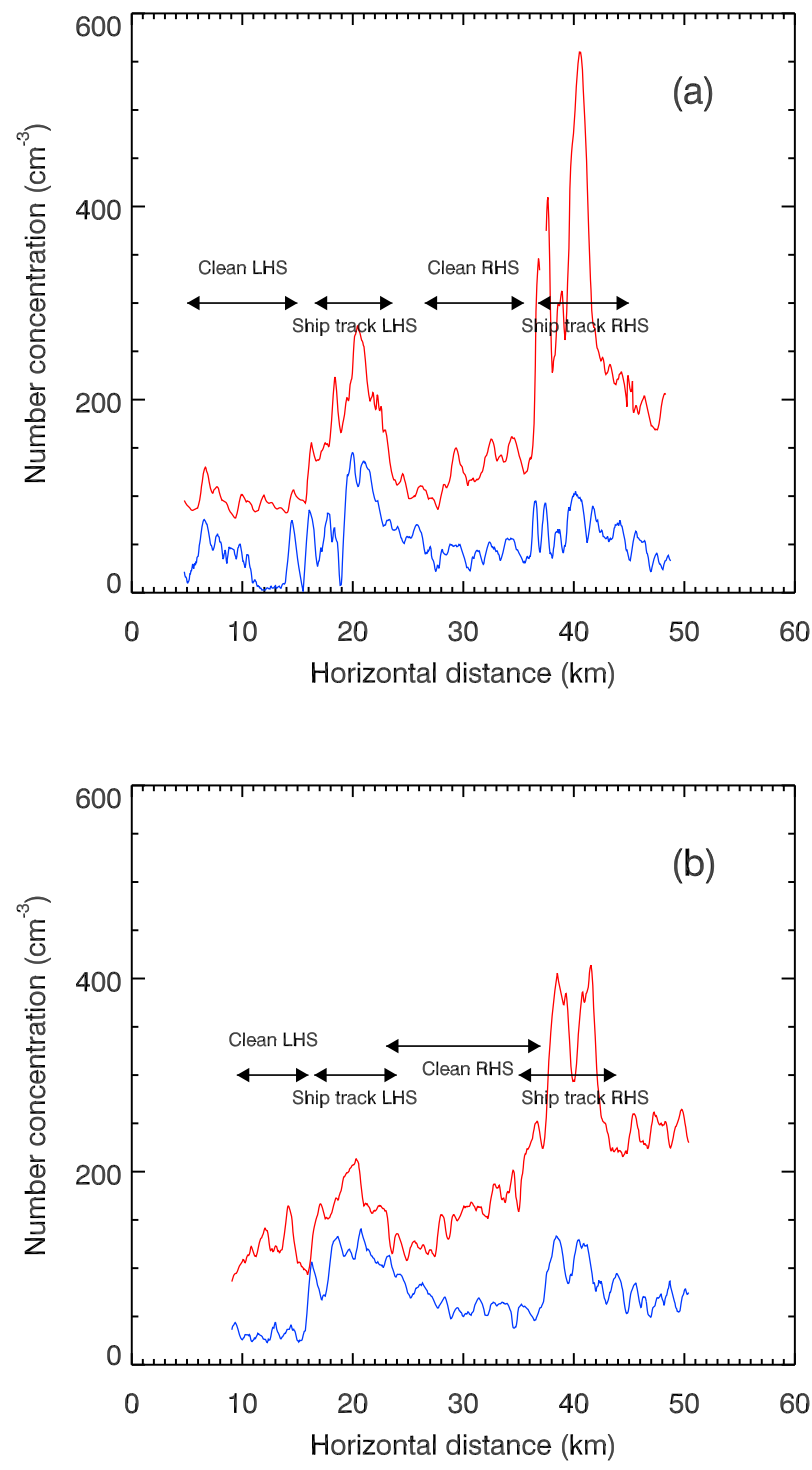

Figure 2. Cloud droplet (blue) and aerosol number concentrations (red) from two horizontal flight legs in RF8 1: (a) a leg in the lower (leg 2, altitude $=189 \mathrm{~m}$ ) and (b) middle (leg 6 , altitude $=271 \mathrm{~m}$ ) portion of the cloud. From the spatial features of aerosol number concentration, as well as those shown in Figure 1, we are able to discern the two ship tracks and the relatively cleaner regions surrounding them (see arrows). Data are smoothed in the forward direction in $10 \mathrm{~s}$ intervals.

entrainment mixing and droplet collision and coalescence, in agreement with the data in Figure $3 b$.

\section{Case Studies}

\subsection{Vertical Profiles}

[8] Vertical profiles of mean cloud properties for each of the five cases of detailed cloud profiling are shown in Figure 4. Most cloud bases were below or around $200 \mathrm{~m}$, except RF11 (Table 1); cloud tops show a larger variation than bases, $350-900 \mathrm{~m}$ with most around $680 \mathrm{~m}$. Mean cloud LWC increases monotonically with height to a maximum below cloud top, and then at the cloud top it rapidly decreases due to entrainment and rainwater depletion. The deviation of the measured cloud LWC from its adiabatic value is best described by the adiabatic ratio, $A R_{L}$. As illustrated in Figure 5, the $A R_{L}$ values for most cloud cases inside the cloud, excluding the cloud top and base, are about $0.7-0.9$, which can be considered as quasi-adiabatic (i.e., using the criteria in section 2). Cloud droplet effective radius $\left(r_{e}\right)$ also increases from base toward a maximum value near the cloud top. The spread of $r_{e}$ in Figure 4c is related to the concentration of subcloud aerosol, which will be discussed in section 3.2. Figure $4 \mathrm{~d}$ shows that the mean value of cloud droplet relative dispersion $\left(d=\sigma / r_{m}\right)$ tends to decrease with increasing height toward the upper part of the cloud, and then it slightly increases near the cloud top; two cases stay relatively constant throughout the cloud depth. The numerator, $\sigma$, also tends to increase with increasing height (Figure $4 \mathrm{e}$ ). The denominator, $r_{m}$, from its proxy $r_{e}$ shown in Figure 4c, generally increases monotonically with increasing height but with a faster rate than $\sigma$. The vertical trend of $d$ is, thus, basically dominated by the competition of vertical trends between $\sigma$ and $r_{m}$. The largest values of $d$ generally occur near cloud base. The observed relative dispersion is further conditionally averaged separately in the updraft and downdraft regions. Table 2 shows that downdraft-mean dispersion tends to be larger than the updraft mean. The differences between the two mean values are generally largest near cloud base. The observation of largest $d$ values occurring at the cloud base downdraft region is also in agreement with the large-eddy simulation results of the marine Sc based on First International Satellite Cloud Climatology Project (ISCCP) Regional Experiment (FIRE) and Atlantic Stratocumulus Transition Experiment (ASTEX) experiments [Lu and Seinfeld, 2006]. A possible explanation for this behavior is a dynamical mixing mechanism consisting of cloud top entrainment and subsequently between-parcel mixing, similar to the "entity" mixing described by Telford et al. [1984]: if local mixing is homogeneous or somewhere between homogeneous and inhomogeneous, cloud top entrainment mixing broadens the local droplet spectrum. Cloud top parcels are negatively buoyant due to longwave cooling, and as they descend, they further mix with the neighboring unentrained parcels (updraft cells); and if cloud top parcels are not significantly broadened by entrainment mixing, $d$ is largest near cloud base. Depletion of water by drizzle could also help explain the results in Table 2; that is, the downdrafts tend to have larger dispersion because they are more likely to contain precipitation and, therefore, broader droplet size distributions.

[9] Vertical profiles of mean cloud and drizzle properties were generally similar in the two MASE experiments, both in magnitude and vertical trend. A noticeable difference is that many clouds in MASE-II had relatively larger drizzle drops than those in MASE-I. The averaged cloud base mean drizzle drop radius is $29 \mu \mathrm{m}$ (range of $24-35 \mu \mathrm{m}$ ) and $38 \mu \mathrm{m}$ (range of 30-44 $\mu \mathrm{m}$ ) for MASE-I and MASE-II, respectively. The larger cloud base drizzle drops of MASE-II result in a larger cloud base drizzle rate than MASE-I. The mean drizzle drop number concentration $\left(N_{d}\right)$ stay relatively constant values in upper $\sim 50 \%$ of the cloud (excluding cloud top) and then decreases with descending height in and below cloud (Figure 6). The drizzle drop mean radius $\left(r_{d}\right)$ increases monotonically from freshly formed drops near cloud top 

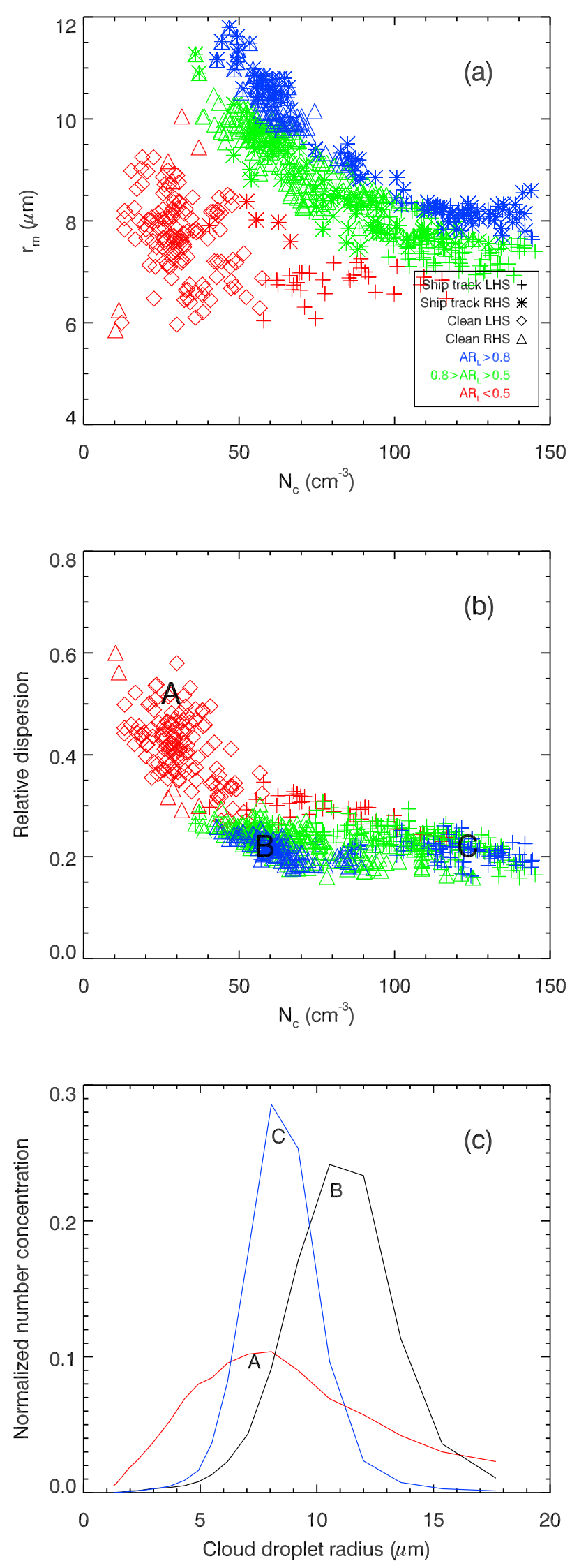

down toward cloud base. The vertical profiles drizzle properties from the two MASE missions suggest that numerous small drizzle drops freshly form in the upper part of the cloud (autoconversion); subsequently, they grow into larger and fewer drops by drizzle accretion of cloud droplets and/or drizzle self collection when falling through the cloud layer. This drizzle formation process as inferred from the MASE measurements is in agreement with previous observations of Sc [Wood, 2005].

\subsection{Ensemble Observations}

[10] Marine boundary layer stratocumulus fields are characterized by complex dynamical structures in which cloud microphysics, turbulence, and drizzle properties are spatially and temporally heterogeneous. To identify aerosolcloud-drizzle relationships, an ensemble approach is adopted in which a sufficient number of data points $(\sim 800$ in MASE-II) are averaged to represent the ensemble properties at the cloud scale. Ensemble measurements of several key parameters from MASE-II are given in Table 1, which represent the mean value over of a horizontal scale of about $40 \mathrm{~km}$. Subcloud aerosol number concentration $\left(N_{a}=230-\right.$ $\left.1400 \mathrm{~cm}^{-3}\right)$, cloud droplet number concentration $\left(N_{c}=70-\right.$ $\left.300 \mathrm{~cm}^{-3}\right)$, cloud depth $(H=210-520 \mathrm{~m})$, cloud liquid water path (LWP) $\left(20-140 \mathrm{~g} \mathrm{~m}^{-2}\right)$, and cloud base drizzle rate $\left(R_{\mathrm{cb}}=0.1-2.7 \mathrm{~mm} \mathrm{~d}^{-1}\right)$ cover a wide range of values.

[11] Ensemble data from MASE-I and MASE-II indicate a direct dependence of $N_{c}$ on subcloud aerosol number concentration (Figure 7a). The ideal adiabatic values of cloud droplet number concentration $\left(N_{c, \text { ad }}\right)$ clearly exceed the measured leg-mean values, $N_{c}$, for MASE-II, as a result of entrainment mixing and drizzle scavenging. The green line in Figure 7a shows a robust regression result of $N_{c \text {, ad }}$ against $N_{a}$. The inverse dependence of cloud top effective radius $\left(r_{e}\right)$ on $N_{c}$ (Figure $7 \mathrm{~b}$ ) from MASE-I and MASE-II and the strong positive dependence of $N_{c}$ on $N_{a}$ are indicative of aerosol microphysical effects.

[12] Unlike the case study of RF8 (Figure 3) that shows a clear inverse relationship between relative dispersion and $N_{c}$, the ensemble results of all clouds sampled in MASE-I

Figure 3. (a) Relationship between cloud droplet mean radius and cloud droplet number concentration and (b) relationship between relative dispersion and cloud droplet number concentration in RF8_1 for leg 6, altitude $=271 \mathrm{~m}$. In Figure 3, data from the ship track region and the clean regions, as identified in Figure 2, are represented by different symbols. The data are sorted according to the following criteria: quasi-adiabatic, $A R_{L} \geq 0.8$ (blue); moderately diluted, $0.8>A R_{L} \geq 0.5$ (green); and strongly diluted, $A R_{L}<0.5$ (red). (c) Cloud droplet number concentration normalized by its total number as a function of cloud droplet radius. The red curve (curve A) is the averaged size distribution for large dispersion $(d \geq 0.4$ and $N_{c} \leq 40 \mathrm{~cm}^{-3}$ ) data seen in Figure $3 \mathrm{~b}$. The blue curve (curve C) corresponds to small dispersion ( $d \leq 0.25, N_{c} \geq$ $100 \mathrm{~cm}^{-3}$, and $A R_{L} \geq 0.8$ ). The black curve (curve $\mathrm{B}$, $d \leq 0.25,60 \mathrm{~cm}^{-3} \geq \bar{N}_{c} \geq 50 \mathrm{~cm}^{-3}$, and $A R_{L} \geq 0.8$ ) serves as the middle case between curve $\mathrm{A}$ and curve $\mathrm{C}$. The averaged drizzle droplet number concentrations in regions $\mathrm{A}, \mathrm{B}$, and $\mathrm{C}$ are $0.86,0.32$, and $0.19 \mathrm{~cm}^{-3}$, respectively. 

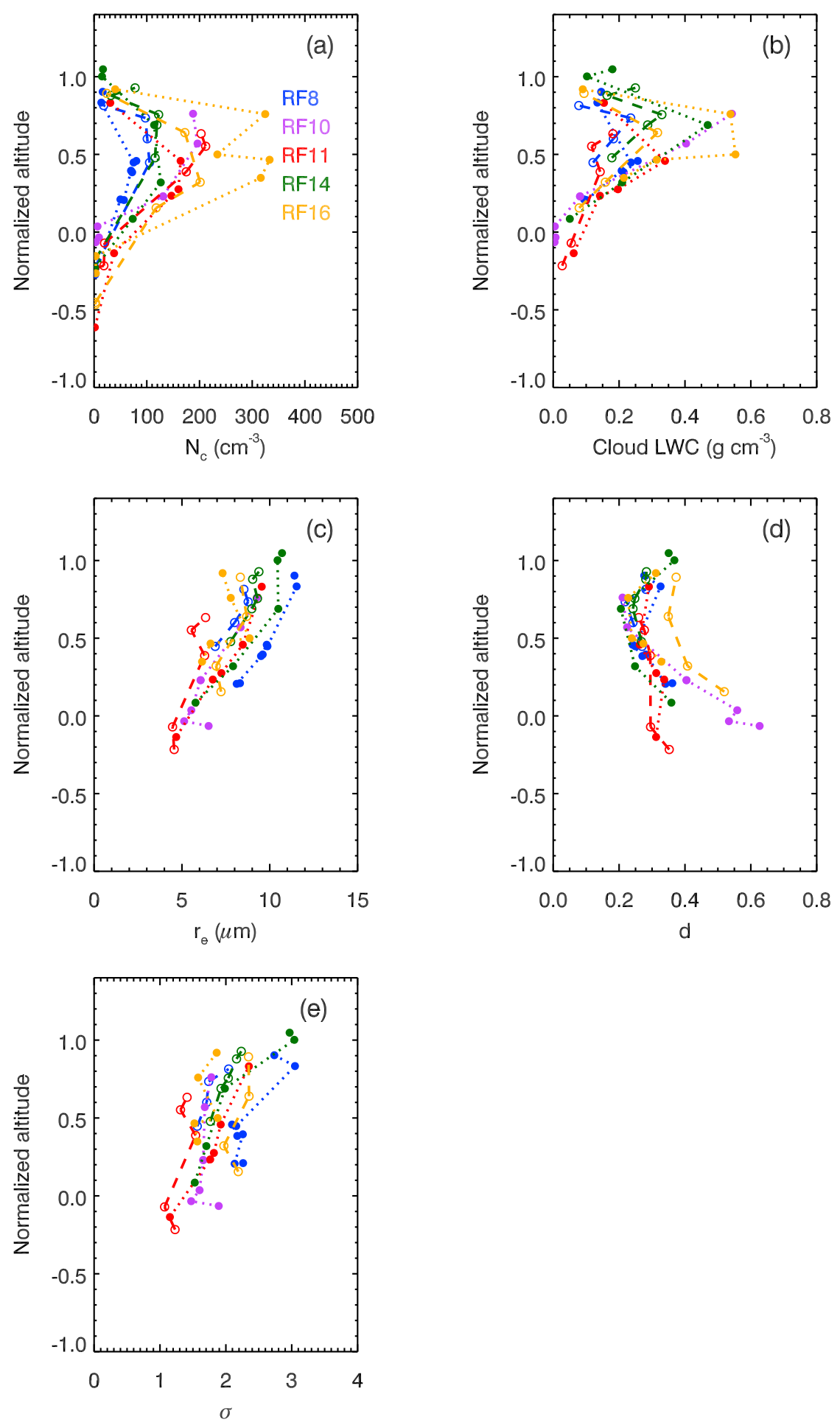

Figure 4. Vertical profiles of leg-mean (a) cloud droplet number concentration, (b) cloud liquid water content, (c) cloud droplet effective radius, and (d) cloud droplet relative dispersion, and (e) cloud droplet spectral width of the cloud cases studied in MASE-II. The vertical axis is the normalized altitude relative to cloud depth. The dotted line with closed circle is the first cloud sampling and the dashed line with open circle is the second cloud sampling. See Table 1 for the two consecutive sampling runs.

and MASE-II exhibit no obvious relationship between relative dispersion and $N_{c}$ (Figure $7 \mathrm{c}$ ). We also do not find any dependence of the ensemble dispersion on cloud base updraft velocity as suggested by adiabatic growth theory [Liu et al., 2006]. Interestingly, ensemble measurements of continental cumuli in the highly polluted Houston area also show no discernable relationship between relative dispersion and subcloud aerosol number concentration [Lu et al., 2008]. The fact that the $N_{c}-d$ relationship is evident in the specific case studies but not in the ensemble average would 


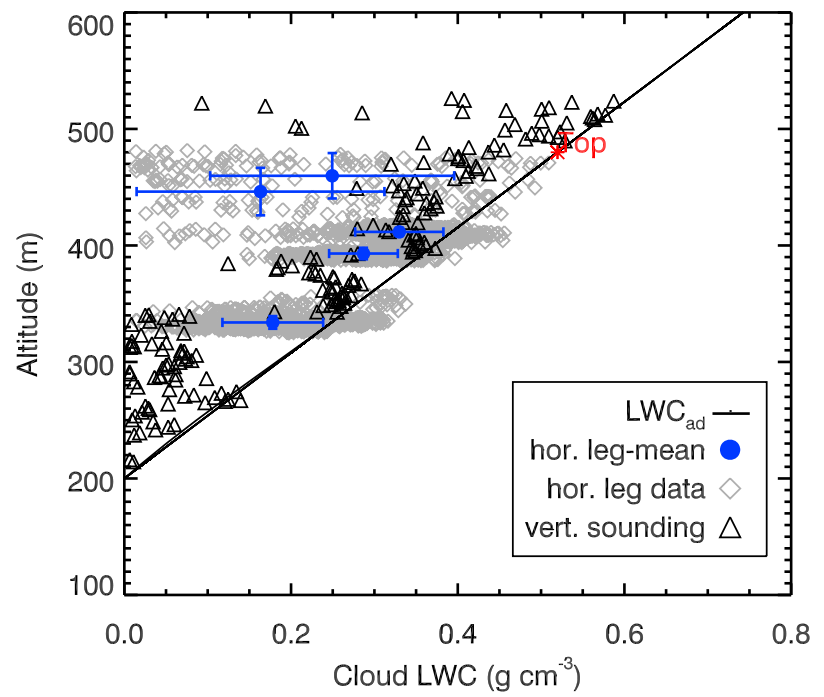

Figure 5. Vertical profiles of the typical cloud LWC and sounding data (RF14_2). Cloud base is determined thermodynamically using the environmental sounding data (triangles). Cloud top (denoted by the red asterisk) is located at where the minimum cloud LWC or droplet number concentration at the "wheel-in" leg. Adiabatic LWC (black line) is calculated using pressure and temperature values from the sounding data at cloud base. Gray diamonds denote the $1 \mathrm{~s}$ data from the horizontal leg flights. Blue circles are the mean value of the horizontal flight data. Error bar is the standard deviation of the data.

appear to be the result of averaging of many different conditions (e.g., parcels with different mixing histories, cloud base updraft velocity, in-cloud turbulence intensity, and dilutions) together that tends to obscure these subtle effects.

\subsection{Aerosol-Cloud-Drizzle Relationship}

[13] A relationship that has received attention is that between cloud base drizzle rate, $R_{\mathrm{cb}}$, LWP, and cloud droplet number concentration, $N_{c}$. Simulations [Nicholls, 1987; Austin et al., 1995; Khairoutdinov and Kogan, 2000; Sorooshian et al., 2009] as well as field studies [Pawlowska and Brenguier, 2003; Comstock et al., 2004; van Zanten et al., 2005; Wood, 2005] show that cloud base drizzle rate can be expressed in terms of cloud LWP (or cloud depth, $H$ ) and $N_{c}$. This relationship can be expressed as $R_{\mathrm{cb}} \propto H^{a 1} N_{c}^{-a 2}$ or $R_{\mathrm{cb}} \propto \mathrm{LWP}^{b 1} N_{c}^{-b 2}$. In particular, the following correlations have been suggested from previous field programs: (1) Second Aerosol Characterization Experiment (ACE-2) $a_{1}=4, a_{2}=1$ [Pawlowska and Brenguier, 2003; Geoffroy et al., 2008]; (2) Second Dynamics and Chemistry of Marine Stratocumulus (DYCOMS-II) $a_{1}=3, a_{2}=1$ [van Zanten et al., 2005]; and (3) Eastern Pacific Investigation of Climate 2001 (EPIC) $b_{1}=1.75, b_{2}=1.75$ [Comstock et al., 2004]. Similar results are obtained from modeling studies [Geoffroy et al., 2008; Wang and Feingold, 2009].

[14] Values of $R_{\mathrm{cb}}$ versus $N_{c}$ are shown in Figure 8a from these field experiments and MASE-I and MASE-II, which demonstrate the inverse proportionality between $R_{\mathrm{cb}}$ and $N_{c}$. From Figure $7 \mathrm{a}$, we can further infer that $R_{\mathrm{cb}}$ is also inversely proportional to subcloud $N_{a}$. The first sampling of research flight 16 (RF16_1) is in many respects an ideal case since its LWP is high (increased potential for drizzle) but its $N_{c}$ is also high (reduced potential for drizzle). On the whole, data from MASE-I and MASE-II are consistent with the modulation of drizzle by variations in subcloud aerosol. A similar case from Wood [2005], flight A641, also shows drizzle suppression at high $N_{c}$ even for quite high LWP. Drizzle formation is strongly dependent on the LWC so that, in Sc, the dependence of cloud base drizzle rate on $H$ should be considered as well. In Figure $8 \mathrm{~b}$ the data are plotted as $R_{\mathrm{cb}}$ versus $H^{3} / N_{c}$. Each line is a regression result through the data of a particular experiment, with the solid line representing MASE-I and MASE-II, the dotted line for ACE-2, and the dashed line for DYCOMS-II. The slopes of the black lines suggest reasonable agreement with the scaling law, $R_{\mathrm{cb}} \propto H^{3} / N_{c}$, the slope of which is plotted as a gray line in the lower right hand corner of Figure 8b. Deviations of the data over different experiments can be attributed, in part, to the specific platform or data retrieving method [Wood, 2005]. Figure $8 \mathrm{c}$ shows the data plotted according to the scaling law of Comstock et al. [2004], $R_{\mathrm{cb}} \propto\left(\mathrm{LWP} / N_{c}\right)^{1.75}$, based on Sc sampled in EPIC 2001. For a cloud in which LWC increases linearly with height [Brenguier et al., 2000], LWP $\propto H^{2}$, and this scaling law can be expressed as $R_{\mathrm{cb}} \propto H^{3.5} / N_{c}^{1.75}$.

[15] The current field measurements of marine boundary layer Sc support previous experiments that cloud base drizzle rate at the ensemble cloud scale can be correlated in terms of, $H$ (or LWP) and $N_{c}$. The present data are largely consistent with the empirical scaling law, $R_{\mathrm{cb}} \propto H^{3} / N_{c}$. Since $R_{\mathrm{cb}}$ tends to be more highly sensitive to the meteorological parameter, $H$, than to the microphysical parameter, $N_{c}$, an accurate estimate of cloud depth is important when using the scaling law to estimate the cloud base drizzle rate.

\section{Precipitation Susceptibility}

[16] It is of interest to quantify the magnitude of aerosol effects on precipitation of eastern Pacific clouds. A new framework to study aerosol effects on precipitation termed

Table 2. Updraft-Mean and Downdraft-Mean Dispersion

\begin{tabular}{ccc}
\hline Altitude $(\mathrm{m})$ & $\begin{array}{c}\text { Updraft-Mean } \\
\text { Dispersion }\end{array}$ & $\begin{array}{c}\text { Downdraft-Mean } \\
\text { Dispersion }\end{array}$ \\
\hline & $R F 8 \_1$ & \\
249 & 0.27 & 0.29 \\
270 & 0.22 & 0.25 \\
& $R F 8 \_2$ & \\
284 & 0.28 & 0.30 \\
& $R F 10$ & \\
293 & 0.41 & 0.48 \\
302 & 0.28 & 0.36 \\
471 & 0.21 & 0.23 \\
568 & 0.20 & 0.21 \\
& $R F 14 \_1$ & \\
216 & 0.25 & 0.36 \\
314 & 0.22 & 0.25 \\
470 & 0.19 & 0.21 \\
& $R F 16 \_1$ & \\
350 & 0.28 & 0.34 \\
410 & 0.25 & 0.28 \\
& $R F 16 \_2$ & \\
332 & 0.34 & 0.53 \\
398 & 0.27 & 0.41 \\
\hline
\end{tabular}



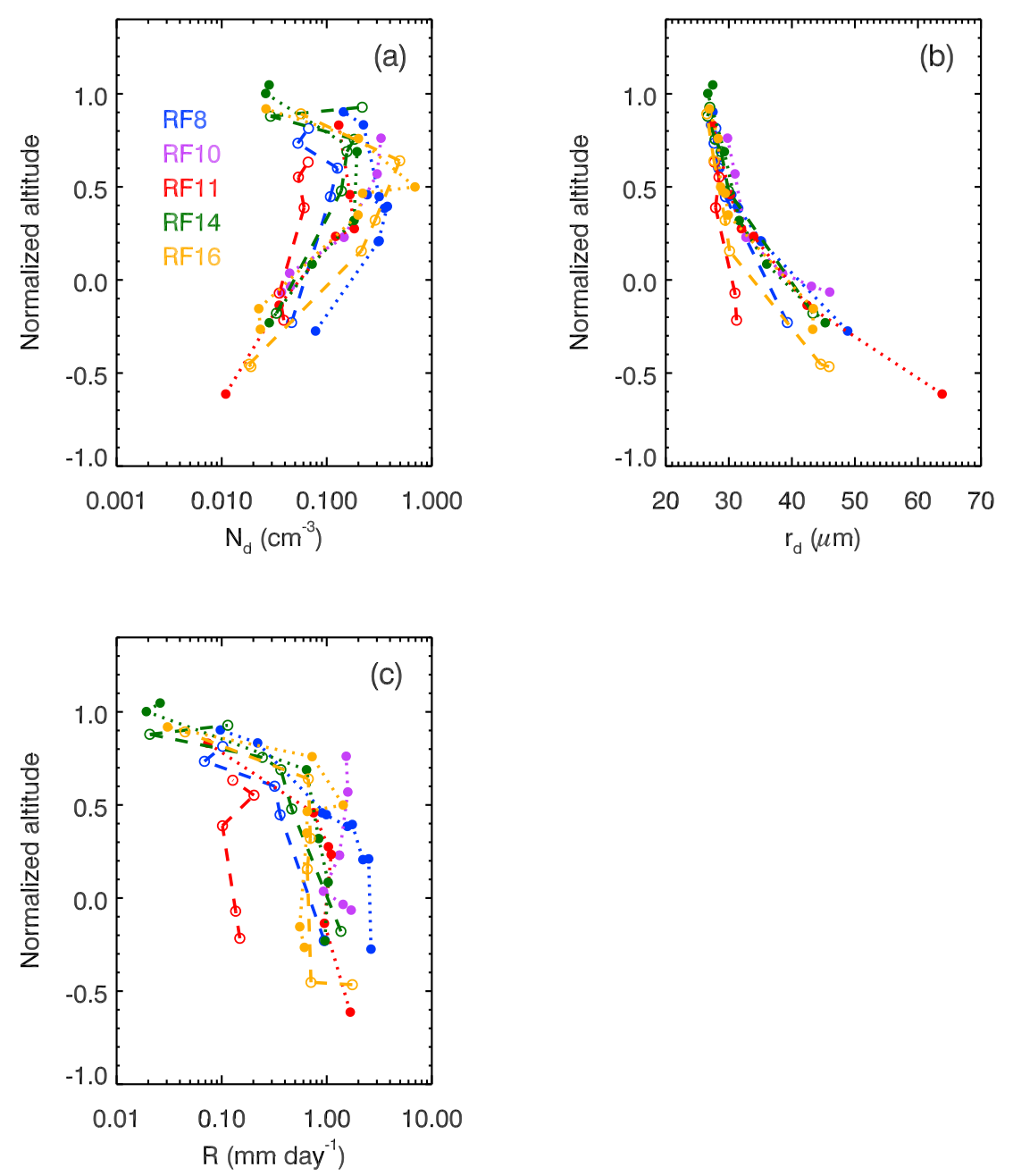

Figure 6. Similar to Figure 4 but for (a) drizzle drop number concentration, (b) drizzle drop mean radius, and (c) drizzle flux.

the precipitation susceptibility $\left(S_{\mathrm{o}}=-d \ln R / d \ln N_{c}\right)$ has recently been proposed [Feingold and Siebert, 2009; Sorooshian et al., 2009]. It relates a change in precipitation rate to a perturbation in cloud droplet number concentration and can be directly related to the power law forms in section 3. Models of varying complexity and observations from NASA's A-Train constellation of satellites indicate the existence of three $S_{o}$ regimes [Sorooshian et al., 2009]: (1) low LWP $\left(\leq 500 \mathrm{~g} \mathrm{~m}^{-2}\right)$, where $S_{\mathrm{o}}$ is relatively low because clouds cannot generate much precipitation, regardless of the aerosol concentration; (2) intermediate LWP $\left(\sim 500-1000 \mathrm{~g} \mathrm{~m}^{-2}\right)$, where the precipitating potential of clouds is no longer limited by LWP, but that larger $N_{c}$, and consequently reduced collision coalescence, suppresses precipitation; and (3) large LWP $\left(\geq 1000 \mathrm{~g} \mathrm{~m}^{-2}\right)$, where increasing LWP dominates precipitation formation regardless of $N_{c}$. Thus, LWP can be viewed as establishing the potential to which a cloud might be able to precipitate, and $N_{c}$ can be viewed as regulating the precipitation. Although the LWP bounds of these regimes are still uncertain and likely variable for differing atmospheric regimes (the results from Sorooshian et al. [2009] are applicable to tropical shallow cumulus clouds in unstable atmospheric conditions), the MASE-I and MASE-II aircraft measurements offer a first-of-a-kind opportunity to directly quantify $S_{o}$ with simultaneous satellite measurements, for a single cloud type within a fixed region and season growing under similar atmospheric conditions; these homogeneous conditions increase the likelihood of discerning a pure aerosol effect on precipitation.

[17] We quantify the satellite-derived value of the precipitation susceptibility for a region encompassing the spatial domain of the MASE-I and MASE-II aircraft flights $\left(41^{\circ} \mathrm{N}\right.$, $34^{\circ} \mathrm{N} ; 134^{\circ} \mathrm{W}, 122^{\circ} \mathrm{W}$ ) and for the month of July in years 2006-2008. The methodology for quantifying this value with A-Train data is summarized by Sorooshian et al. [2009]. Since $N_{c}$ is not quantified directly with satellite data, we calculate $S_{o}{ }^{\prime}=-(d \ln R) /(d \ln \alpha)$, where $R$ is precipitation rate and $\alpha$ represents a proxy for subcloud cloud condensation nuclei $(\mathrm{CCN})$ concentration. We use aerosol index (AI) (AI equals aerosol optical depth times Ångstrom exponent) as the CCN proxy; AI has been shown to correlate better with cloud properties and columnar aerosol concentrations as compared to aerosol optical depth [Nakajima et al., 2001]. The two forms of susceptibility are related by $S_{o}^{\prime} \sim c S_{o}$, where $N_{c} \sim \alpha^{c}(c=0.563$ for MASE-I, and $c=0.594$ for MASE-II from $N_{c} \propto N_{a}^{c}$ ). We use CloudSat data for precipitation rate, Advanced Microwave Scanning 

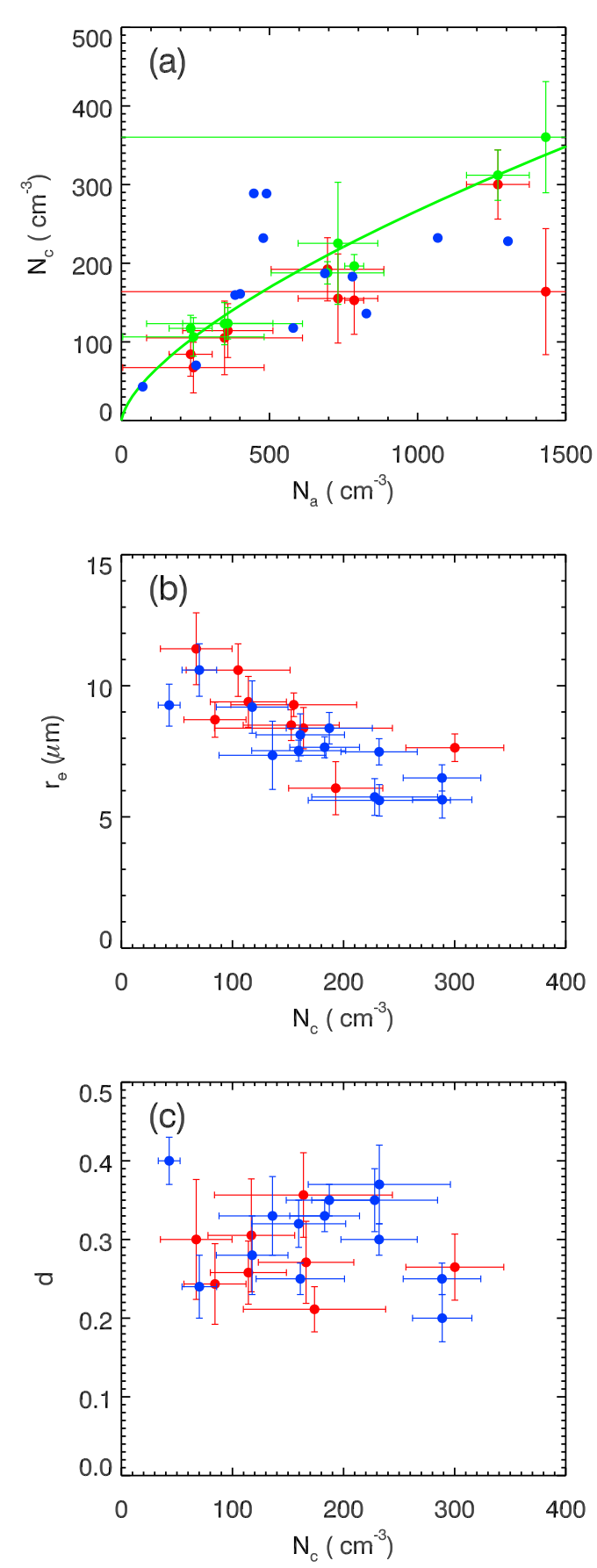

Figure 7. (a) Subcloud aerosol number concentration $\left(N_{a}\right)$ versus cloud droplet number concentration $\left(N_{c}\right)$, (b) cloud top effective radius $\left(r_{e}\right)$, and (c) cloud top relative dispersion (d) versus $N_{c}$. Data points in blue (MASE-I) and red (MASE-II) are the leg-averaged values for each cloud case during MASE-I and MASE-II missions. Green points are the leg-mean adiabatic cloud droplet number concentration $\left(N_{c, \text { ad }}\right)$ for MASE-II; the green line in Figure $7 \mathrm{a}$ is the regression result of the green points $\left(N_{c, \text { ad }}=3.033 N_{a}^{0.644}\right.$, $\left.R^{2}=0.96\right)$. For better viewing of Figure 7a, MASE-I data are plotted without error bars.
Radiometer (AMSR-E) for LWP, and Moderate Resolution Imaging Spectroradiometer (MODIS) for AI. With regard to the ability of CloudSat to detect precipitation in the region of interest, Haynes et al. [2009] provide a detailed description of the CloudSat level 2C-PRECIP-COLUMN product that is used to quantify rain rate and distinguish between raining and nonraining scenes. The sensitivity of attenuation to rainfall is greatest for small rain rates, where a lower rain rate limit of $0.1 \mathrm{~mm} \mathrm{~h}^{-1}$ is employed in this study. Rain rate retrievals below $0.1 \mathrm{~mm} \mathrm{~h}^{-1}$ suffer from relatively high uncertainty as to whether attenuation is due to cloud or rainwater, but this drops off quickly at higher $R$ [Haynes et al., 2009]. The 2CPRECIP-COLUMN product is also used to remove cases of multiple cloud layers, where lowest clutter-free range gate above the surface is between 600 and $840 \mathrm{~m}$ [Haynes et al., 2009]. Extra caution was taken in the satellite data analysis to remove biases associated with cloud effects on aerosol via wet scavenging [Sorooshian et al., 2009] by employing the Precipitation Estimation from Remotely Sensed Information using Artificial Neural Networks (PERSIANN) [Sorooshian et al., 2000]) product to remove instances of precipitating events prior to A-Train overpasses.

[18] Cloud scenes with LWP between 50 and $300 \mathrm{~g} \mathrm{~m}^{-2}$ are analyzed (We use a higher LWP upper bound than the observations to have enough data points for statistical analysis), and we note that these clouds are all characterized by values of lower tropospheric static stability (LTSS) (LTSS is the potential temperature difference between 700 and $1000 \mathrm{hPa}$; [Klein and Hartmann, 1993]) in excess of $20^{\circ} \mathrm{C}$, indicating a high degree of atmospheric stability and dynamical suppression. LTSS estimates were derived from the European Centre for Medium Range Weather Forecasts (ECMWF) analyses that have been matched to the CloudSat footprint (ECMWF-AUX product). At constant $H$ (or LWP), the exponent $a_{2}$ (or $b_{2}$ ) from above can be equated to $S_{o}$. The MASE-I and MASE-II aircraft measurements suggest that $S_{o}=0.81$ (fixed $H$ ) and 1.06 (fixed LWP) (Figure 8). For the LWP range of $50-300 \mathrm{~g} \mathrm{~m}^{-2}$, results from a cloud parcel model and separate large eddy simulations of ASTEX and FIRE stratocumulus clouds indicate that $S_{o}$ is on the order of 0.67 [Feingold and Siebert, 2009; Wang and Feingold, 2009]. The satellite-derived value of $S_{o}{ }^{\prime}$ is 0.42 and the corresponding $S_{o}$ value using aircraft measurements ranges between $0.46-0.48$ (fixed $H$ ) and $0.60-0.63$ (fixed LWP). Using the aircraft-measured $c$ values, the model-derived $S_{o}{ }^{\prime}$ ranges between 0.38 and 0.40 , which is in close agreement with the satellite-derived value and aircraft measurement at constant $H$. We note that the aircraft- and large-eddy-simulation-based precipitation rate data correspond to the cloud base value, whereas CloudSat precipitation rates are based on path-integrated attenuation measurements. The range of $S_{o}^{\prime}$ values can likely be explained by the differences in the quantification techniques (model, aircraft, or satellite) and subtle differences in the macrophysical conditions in which the probed or simulated clouds were evolving in, but it is still remarkable that there is a high level of agreement between the model simulations and the various measurements presented. These results provide some confidence that the new generation of satellite remote sensors can help constrain the magnitude of the precipitation susceptibility of clouds to 
aerosol perturbations. It is also worthy of mention that other recent work has employed satellite observations and modeling to attempt to address issues related to aerosol effects
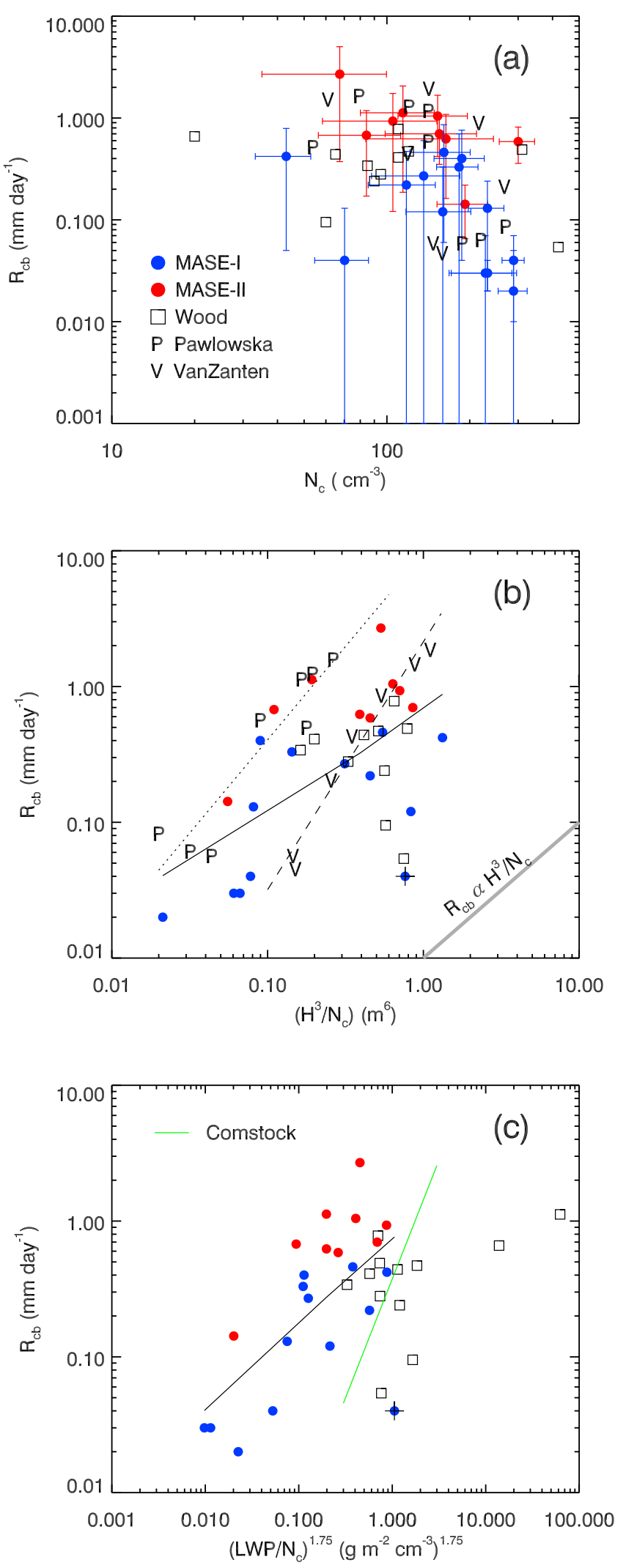

on precipitation in marine low warm clouds [e.g., Kubar et al., 2009; L'Ecuyer et al., 2009; Wood et al., 2009].

\section{Conclusions}

[19] We present observational data on aerosol-cloud relationships in marine stratocumulus from the MASE-II campaign carried out in July 2007 over the eastern Pacific Ocean near Monterey, California. Data are compared with those obtained in the MASE-I experiment of July 2005 carried out in the same region, as well as with those from other marine stratocumulus measurement campaigns, DYCOMS-II, ACE-2, and EPIC, and A-Train satellite observations. Ensemble cloud measurements over both MASE-I and MASE-II show that increased cloud droplet number concentration and decreased cloud top effective radius are associated with increased subcloud aerosol concentration. These observations, carried out over regions of essentially uniform meteorology in the presence of aerosol perturbations resulting from ship exhaust ("ship tracks"), are in accord with those from other field campaigns. The strength of this effect is seen to depend on the extent to which the profile of liquid water content is adiabatic. While one case study exhibits an inverse relationship between cloud droplet relative dispersion and cloud droplet number concentration, the ensemble of observations from MASE-I and MASE-II show no clear relationship between relative dispersion and $N_{c}$. This is likely a consequence of the fact that averaging of many different conditions together tends to obscure the subtle effects that combine to govern relative dispersion. Observations of cloud base drizzle rate and aerosol/cloud number concentrations in both MASE experiments demonstrate the modulation of drizzle by variations in subcloud aerosol levels. The relationship between the observed cloud base drizzle rate $R_{\mathrm{cb}}$ and $N_{c}$, are consistent with the proportionality, $R_{\mathrm{cb}} \propto H^{3} / N_{c}$, where $H$ is cloud depth. Simultaneous aircraft and satellite observations indicate that the precipitation susceptibility of eastern Pacific

Figure 8. (a) Cloud base drizzle rate $\left(R_{\mathrm{cb}}\right)$ versus cloud droplet number concentration $\left(N_{c}\right)$. Blue and red circles are the mean values from MASE-I and MASE-II, respectively. Data of van Zanten et al. [2005] and Pawlowska and Brenguier [2003] are from the DYCOMS-II and ACE-2, respectively. Note that the values of Pawlowska and Brenguier [2003] were obtained from Figure 1 of Wood [2005]. (b) $R_{\mathrm{cb}}$ versus $H^{3} / N_{\mathrm{c}}$. The solid black line is the multiregression result through MASE-I and MASE-II data arbitrarily excluding the point marked with a cross $\left(R_{\mathrm{cb}}=\right.$ $\left.8.04 \times 10^{-5} H^{2.07} N_{c}^{-0.81}, R^{2}=0.37\right)$. The dashed line is the regression result for the DYCOMS-II data. The dotted line is the regression result for the ACE-2 data. The gray line in the lower right corner demonstrates the proportionality between $R_{\mathrm{cb}}$ and $H^{3} / N_{c}$. (c) $R_{\mathrm{cb}}$ versus $\left(\mathrm{LWP} / N_{c}\right)^{1.75}$, where LWP is liquid water path. The green line represents the parameterization of Comstock et al. [2004] $\left(R_{\mathrm{cb}}=0.374\right.$ $\left.\left(\mathrm{LWP} / N_{c}\right)^{1.75}\right)$, which is the best fit of the observations from the EPIC experiment. The solid black line is the multiregression through both MASE-I and MASE-II data, also excluding MASE-I point (cross) $\left(R_{\mathrm{cb}}=0.54 \mathrm{LWP}^{1.13}\right.$ $\left.N_{c}^{-1.06}, R^{2}=0.42\right)$. All parameters have the same unit as in Table 1 . 
clouds to aerosol perturbations ranges between $S_{o}{ }^{\prime}=0.42$ and $S_{o}{ }^{\prime}=0.63$. Observations of aerosol effects on marine stratocumulus presented here add to the existing body of data, which can serve as constraints in the evaluation of modeling studies of the effect of aerosol perturbations on marine stratocumulus properties. Nevertheless, cloud feedback mechanisms that ensue once an aerosol perturbation occurs [Wood, 2007] continue to remain observationally challenging.

[20] Acknowledgments. This work was supported by the Office of Naval Research grant N00014-04-1-0018. A.S. acknowledges support from the Cooperative Institute for Research in the Atmosphere Postdoctoral Research Program. G.F. acknowledges NOAA's Climate Goal. The authors acknowledge Robert Wood for helpful comments.

\section{References}

Austin, P., Y. N. Wang, R. Pincus, and V. Kujala (1995), Precipitation in stratocumulus clouds: Observational and modeling results, J. Atmos. Sci., 52, 2329-2352, doi:10.1175/1520-0469(1995)052<2329:PISCOA $>$ 2.0.CO;2.

Brenguier, J. L., and R. Wood (2009), Observational strategies from the micro- to mesoscale, in Clouds in the Perturbed Climate System: Their Relationship to Energy Balance, Atmospheric Dynamics, and Precipitation, edited by J. Heintzenberg and R. J. Charlson, pp. 487-510, MIT Press, Cambridge, Mass.

Brenguier, J. L., H. Pawlowska, L. Schüller, R. Preusker, J. Fischer, and Y. Fouquart (2000), Radiative properties of boundary layer clouds: Droplet effective radius versus number concentration, J. Atmos. Sci., 57, 803-821, doi:10.1175/1520-0469(2000)057<0803:RPOBLC $>2.0 . C O ; 2$.

Comstock, K. K., R. Wood, S. E. Yuter, and C. S. Bretherton (2004), Reflectivity and rain rate in and below drizzling stratocumulus, Q. J. R. Meteorol. Soc., 130, 2891-2918, doi:10.1256/qj.03.187.

Feingold, G., and H. Siebert (2009), Cloud-aerosol interactions from the micro to the cloud scale, in Clouds in the Perturbed Climate System. Their Relationship to Energy Balance, Atmospheric Dynamics, and Precipitation, edited by J. Heintzenberg and R. J. Charlson, pp. 319-338, MIT Press, Cambridge, Mass.

Geoffroy, O., J.-L. Brenguier, and I. Sandu (2008), Relationship between drizzle rate, liquid water path and droplet concentration at the scale of a stratocumulus cloud system, Atmos. Chem. Phys., 8, 4641-4654.

Haynes, J. M., T. S. L'Ecuyer, G. L. Stephens, S. D. Miller, C. Mitrescu, N. B. Wood, and S. Tanelli (2009), Rainfall retrieval over the ocean with spaceborne W-band radar, J. Geophys. Res., 114, D00A22, doi:10.1029/2008JD009973.

Hersey, S. P., A. Sorooshian, S. M. Murphy, R. C. Flagan, and J. H. Seinfeld (2009), Aerosol hygroscopicity in the marine atmosphere: A closure study using high-resolution, size-resolved AMS and multipleRH DASH-SP data, Atmos. Chem. Phys., 9, 2543-2554.

Intergovernmental Panel on Climate Change (2007), Climate Change: The Physical Science Basis: Contribution of Working Group I to the Fourth Assessment Report of the Intergovernmental Panel on Climate Change, Cambridge Univ. Press, New York.

Khairoutdinov, M., and Y. Kogan (2000), A new cloud physics parameterization in a large-eddy simulation model of marine stratocumulus, Mon Weather Rev., 128, 229-243, doi:10.1175/1520-0493(2000)128<0229: ANCPPI $>2.0 . \mathrm{CO} ; 2$.

Klein, S. A., and D. L. Hartmann (1993), The seasonal cycle of low stratiform clouds, J. Clim., 6, 1587-1606, doi:10.1175/1520-0442(1993)006< 1587:TSCOLS $>2.0$. CO;2.

Kubar, T., D. Hartmann, and R. Wood (2009), Understanding the importance of microphysics and macrophysics for warm rain in marine low clouds. Part I. Satellite observations, J. Atmos. Sci., 66, 2953-2972, doi:10.1175/2009JAS3071.1.

L'Ecuyer, T. S., W. Berg, J. Haynes, M. Lebsock, and T. Takemura (2009), Global observations of aerosol impacts on precipitation occurrence in warm maritime clouds, J. Geophys. Res., 114, D09211, doi:10.1029/ 2008JD011273

Liu, Y., and P. H. Daum (2002), Anthropogenic aerosols: Indirect warming effect from dispersion forcing, Nature, 419, 580-581, doi:10.1038/ 419580a.

Liu, Y., P. H. Daum, and S. S. Yum (2006), Analytical expression for the relative dispersion of the cloud droplet size distribution, Geophys. Res. Lett., 33, L02810, doi:10.1029/2005GL024052.
Lu, M.-L., and J. H. Seinfeld (2006), Effect of aerosol number concentration on cloud droplet dispersion: A large-eddy simulation study and implications for aerosol indirect forcing, J. Geophys. Res., 111, D02207, doi:10.1029/2005JD006419.

Lu, M.-L., W. C. Conant, H. H. Jonsson, V. Varutbangkul, R. C. Flagan, and J. H. Seinfeld (2007), The Marine Stratus/Stratocumulus Experiment (MASE): Aerosol-cloud relationships in marine stratocumulus, J. Geophys. Res., 112, D10209, doi:10.1029/2006JD007985.

Lu, M.-L., G. Feingold, H. H. Jonsson, P. Y. Chuang, H. Gates, R. C. Flagan, and J. H. Seinfeld (2008), Aerosol-cloud relationships in continental shallow cumulus, J. Geophys. Res., 113, D15201, doi:10.1029/2007JD009354.

Nakajima, T., A. Higurashi, K. Kawamoto, and J. E. Penner (2001), A possible correlation between satellite-derived cloud and aerosol microphysical parameters, Geophys. Res. Lett., 28, 1171-1174, doi:10.1029/ 2000GL012186.

Nicholls, S. (1987), A model of drizzle growth in warm, turbulent, stratiform clouds, Q. J. R. Meteorol. Soc., 113, 1141-1170, doi:10.1256/ smsqj. 47804 .

Noone, K. J., et al. (2000), A case study of ship track formation in a polluted marine boundary layer, J. Atmos. Sci., 57, 2748-2764, doi:10.1175/1520-0469(2000)057<2748:ACSOST>2.0.CO;2.

Pawlowska, H., and J. L. Brenguier (2003), An observational study of drizzle formation in stratocumulus clouds for general circulation model (GCM) parameterizations, J. Geophys. Res., 108(D15), 8630, doi:10.1029/2002JD002679.

Pawlowska, H., W. W. Grabowski, and J.-L. Brenguier (2006), Observations of the width of cloud droplet spectra in stratocumulus, Geophys. Res. Lett., 33, L19810, doi:10.1029/2006GL026841.

Platnick, S., and S. Twomey (1994), Determining the susceptibility of cloud albedo to changes in droplet concentration with the advanced very highresolution radiometer, J. Appl. Meteorol., 33, 334-347, doi:10.1175/ 1520-0450(1994)033<0334:DTSOCA $>2.0 . C O ; 2$.

Sorooshian, A., G. Feingold, M. D. Lebsock, H. Jiang, and G. L. Stephens (2009), On the precipitation susceptibility of clouds to aerosol perturbations, Geophys. Res. Lett., 36, L13803, doi:10.1029/2009GL038993.

Sorooshian, S., K.-L. Hsu, X. Gao, H. V. Gupta, B. Imam, and D. Braithwaite (2000), Evaluation of PERSIANN system satellite-based estimates of tropical rainfall, Bull. Am. Meteorol. Soc., 81, 2035-2046, doi:10.1175/1520-0477(2000)081<2035:EOPSSE > 2.3.CO;2.

Stephens, G. L., et al. (2002), The CloudSat mission and the A-Train: A new dimension of space-based observations of clouds and precipitation, Bull. Am. Meteorol. Soc., 83, 1771-1790, doi:10.1175/BAMS-83-12-1771.

Telford, J. W., T. S. Keck, and S. K. Chai (1984), Entrainment at cloud tops and the droplet spectra, J. Atmos. Sci., 41, 3170-3179, doi:10.1175/ 1520-0469(1984)041<3170:EACTAT>2.0.CO;2.

van Zanten, M. C., B. Stevens, G. Vali, and D. H. Lenschow (2005), Observations of drizzle in nocturnal marine stratocumulus, J. Atmos. Sci., 62, 88-106, doi:10.1175/JAS-3355.1.

Wang, H., and G. Feingold (2009), Modeling mesoscale cellular structures and drizzle in marine stratocumulus: Part 1: Impact of drizzle on the formation and evolution of open cells, J. Atmos. Sci., doi:10.1175/ 2009JAS3022.1, in press.

Wood, R. (2005), Drizzle in stratiform boundary layer clouds. Part 1: Vertical and horizontal structure, J. Atmos. Sci., 62, 3011-3033, doi:10.1175/JAS3529.1

Wood, R. (2007), Cancellation of aerosol indirect effects in marine stratocumulus through cloud thinning, J. Atmos. Sci., 64, 2657-2669, doi:10.1175/JAS3942.1.

Wood, R., T. Kubar, and D. Hartmann (2009), Understanding the importance of microphysics and macrophysics for warm rain in marine low clouds. Part II: Heuristic models of rain formation, J. Atmos. Sci., 66, 2973-2990, doi:10.1175/2009JAS3072.1.

G. Feingold, Chemical Sciences Division, Earth System Research Laboratory, NOAA, R/E/CSD2, 325 Broadway, Boulder, CO 80305, USA. R. C. Flagan and J. H. Seinfeld, Department of Chemical Engineering, California Institute of Technology, 1200 E. California Blvd., Mail Code 210-41, Pasadena, CA 91125, USA. (seinfeld@caltech.edu)

H. H. Jonsson, Naval Postgraduate School, 3200 Imjin Rd., Hangar 507, Monterey, CA 93933, USA.

M.-L. Lu, Department of Environmental Science and Engineering, California Institute of Technology, 1200 E. California Blvd., Pasadena, CA 91125, USA.

A. Sorooshian, Department of Chemical and Environmental Engineering, University of Arizona, JW Harshbarger Bldg., PO Box 210011, Tucson, AZ 85721, USA. 